|| ISSN(online): 2589-8698 || ISSN(print): 2589-868X || International Journal of Medical and Biomedical Studies Available Online at www.ijmbs.info

PubMed (National Library of Medicine ID: 101738825) Index Copernicus Value 2017: 40.03

\title{
PATIENTS PREFERENCES REGARDING AGE, SEX \& APPEARANCE OF ORTHODONTISTS
}

\author{
Dr. Shubham Agrawal ${ }^{1}$, Dr. Amit Agrawal ${ }^{2}$ \& Dr. Anuradha Agrawal ${ }^{3}$ \\ ${ }^{1}$ Reader, Department of Orthodontist and Dentofacial Orthopaedic, Modern Dental College and \\ Research Center, Indore \\ ${ }^{2}$ Associate Professor, MGM Medical College, Indore \\ ${ }^{3}$ Reader, Dept. of Pedodontics, Government Dental College, Indore
}

Article Info: Received 14 February 2019; Accepted 12 March. 2019

Cite this article as: Agrawal, Dr. S., Agrawal, Dr. A., \& Agrawal, Dr. A. (2019). PATIENTS PREFERENCES REGARDING AGE, SEX \& APPEARANCE OF ORTHODONTISTS. International Journal of Medical and Biomedical Studies, 3(3).

DOI: https://doi.org/10.32553/ijmbs.v3i3.147

Address for Correspondence: Dr. Amit Agrawal, Associate Professor, MGM Medical College, Indore

Conflict of interest: No conflict of interest.

\section{Abstract}

This Study was conducted at Modern Dental College and Research Center, Indore for 01 year with the sample comprised 200 participants (79 male, 111 female) who were divided into 3 groups.

Patients of all ages consider appearance to be an important factor when choosing an orthodontist. The participants largely preferred younger professionals who dressed in white coats, because this type of attire was considered clean and hygienic.

Keywords: Age, Sex \& Orthodontist

\section{Introduction:}

Patients and health science professionals have long preferred white attire, ${ }^{1}$ which has been used in the medical field since the 19 th century. ${ }^{2}$ The gradual decrease of the popularity of white attire may lead to many medical professionals wearing more formal clothing, such as suits. ${ }^{2}$ This situation is also found in dentistry, where professionals tend to wear alternative attire in both clinical and digital social marketing settings. These may include blazers, suits, ties, and even less formal and colorful wear in pediatric settings.

\section{Material \& Method}

This Study was conducted at Modern Dental College and Research Center, Indore for 01 year with the sample comprised 200 participants (79 males, 111 females) who were divided into 3 groups based on age: group 1 with 70 children aged 8 to 11 years (mean, 9.7 years), group 2 with 70 adolescents aged 12 to 17 years (mean, 14.8 years), and group 3 with 60 young adults aged 18 to 25 years (mean, 20.2 years). This sample size was determined using a power analysis that adopted a significance rate of $5 \%$ and a sample power of $80 \%$ to yield a minimum difference of $20 \%$ between the variables.

All participants were students at local schools and universities who required orthodontic treatment. Students without malocclusion were not included in the sample. Four orthodontists were selected as models: 1 man and 1 woman aged 25 to 30 years, and 1 man and 1 woman aged 40 to 50 years. 
Each participant was interviewed separately using a questionnaire applied by 1 researcher, who assisted with the application but did not interfere with the participant's answers. Each participant analyzed image set 1 and was questioned regarding which orthodontist he or she would choose for treatment. This research step was designed to verify the influences of age and sex on the selection of an orthodontist. The remaining image sets were presented in sequence to investigate the attire preferred by the participants. Data were collected for one year.

The data were explored descriptively and are presented as absolute (numbers) and relative (percentages) frequencies. The chi-square test was used to investigate the participants' preferences for the orthodontists (considering age).

\section{Observation \& Results}

Table 1: Comparison of 3 age groups for an Orthodontist

\begin{tabular}{|l|l|l|l|l|l|l|}
\hline Group & $\mathbf{1}$ & $\mathbf{2}$ & $\mathbf{3}$ & $\mathbf{4}$ & Total & P Value \\
\hline $\mathbf{1}$ & 33 & 19 & 11 & 07 & 70 & 0.036 \\
\cline { 1 - 5 } & 38 & 16 & 09 & 07 & 70 & \\
\cline { 1 - 2 } & 26 & 17 & 12 & 05 & 60 & \\
\hline
\end{tabular}

Different letters indicate statistically significant differences $(P<0.001)$;

Table 2: Comparison of 3 Sex groups for an Orthodontist

\begin{tabular}{|l|l|l|l|l|l|l|}
\hline Group & $\mathbf{1}$ & $\mathbf{2}$ & $\mathbf{3}$ & $\mathbf{4}$ & Total & P Value \\
\hline $\mathbf{1}$ & 29 & 23 & 13 & 05 & 70 & 0.047 \\
\cline { 1 - 5 } & 41 & 13 & 11 & 05 & 70 & \\
\cline { 1 - 2 } & 25 & 16 & 12 & 07 & 60 & \\
\hline
\end{tabular}

Different letters indicate statistically significant differences $(P<0.001)$;

\section{DISCUSSION}

Andréa Maria et al Young ${ }^{3}$ female orthodontists were preferred (41.1\%). A white coat was the preferred appearance (48.1\%), followed by social clothing (31.7\%) and a thematic pediatric coat (19.7\%). Groups 1 and 2 preferred a young female orthodontist, whereas group 3 had no apparent age and sex preferences. Regarding attire, group 1 preferred social clothing, whereas groups 2 and 3 preferred a white coat. ${ }^{4}$

Despite investing in marketing tools with the intent of reaching new patients as well as maintaining good relationships with patients already undergoing treatment, orthodontists must remain aware of patients opinions. ${ }^{5}$ As noted above, orthodontists have gradually changed their appearance from the traditional white to more contemporary outfits. ${ }^{6}$ In this investigation, we proposed an important and scientific approach to justifying the changes observed in the appearance of dentists, especially orthodontists, and additionally investigated whether these changes meet patients expectations. ${ }^{7}$

\section{CONCLUSION}

Patients of all ages consider appearance to be an important factor when choosing an orthodontist among them there are 79 males, 111 females out 
to 200 patients in this study. The participants largely preferred younger professionals who dressed in white coats, because this type of appearance was considered clean and hygienic.

\section{REFERENCES}

1. Menahem S, Shvartzman P. Is our appearance important to our patients? Fam Pract 1998;15:391-7.

2. Aitken SA, Tinning CG, Gupta S, Medlock G, Wood AM, Aitken MA. The importance of the orthopaedic doctors' appearance: a cross-regional questionnaire based study. Surgeon 2014;12:40-6.

3. Andréa Maria deSouza-Constantinoa et al. American Journal of Orthodontics and
Dentofacial Orthopedics Volume 154, Issue 6, December 2018, Pages 829-834.

4. Rehman SU, Nietert PJ, Cope DW, Kilpatrick AO. What to wear today? Effect of doctor's attire on the trust and confidence of patients. Am. J. Med. 2005;118:1279-1286.

5. Menahem S, Shvartzman P. Is our appearance important to our patients? Fam Practice 1998;15:391-397.

6. Gonzalez Del Ray JA, Paul RI. Preferences of parents for pediatric emergency physicians' attire. Pediatr Emerg Care 1995;11:361-364.

7. Major K, Hayase $Y$, Balderrama D, Lefor AT. Attitudes regarding surgeons' attire. Am J Surg 2005;190:103-106. 